\title{
Shortening and Improving the Embryonic Stem Cell Test through the Use of Gene Biomarkers of Differentiation
}

\author{
Andrea C. Romero, Eugenio Vilanova, and Miguel A. Sogorb \\ Unidad de Toxicología y Seguridad Química, Instituto de Bioingeniería, Universidad Miguel Hernández de Elche, \\ Avenida de la Universidad s/n, 03202 Elche, Spain \\ Correspondence should be addressed to Miguel A. Sogorb, msogorb@umh.es
}

Received 11 May 2011; Revised 30 June 2011; Accepted 1 July 2011

Academic Editor: Yujian James Kang

Copyright ( $\odot 2011$ Andrea C. Romero et al. This is an open access article distributed under the Creative Commons Attribution License, which permits unrestricted use, distribution, and reproduction in any medium, provided the original work is properly cited.

\begin{abstract}
The embryonic Stem cell Test (EST) is a validated assay for testing embryotoxicity in vitro. The total duration of this protocol is 10 days, and its main end-point is based on histological determinations. It is suggested that improvements on EST must be focused toward molecular end-points and, if possible, to reduce the total assay duration. Five days of exposure of D3 cells in monolayers under spontaneous differentiation to $50 \mathrm{ng} / \mathrm{mL}$ of the strong embryotoxic 5 -fluorouracil or to $75 \mu \mathrm{g} / \mathrm{mL}$ of the weak embryotoxic 5,5-diphenylhydeantoin caused between 20 and 74\% of reductions in the expression of the following genes: Pnpla6, Afp, Hdac7, $V e g f a$, and Nes. The exposure to $1 \mathrm{mg} / \mathrm{mL}$ of nonembryotoxic saccharin only caused statistically significant reductions in the expression of Nes. These exposures reduced cell viability of D3 cells by 15, 28, and 34\%. We applied these records to the mathematical discriminating function of the EST method to find that this approach is able to correctly predict the embryotoxicity of all three above-mentioned chemicals. Therefore, this work proposes the possibility of improve EST by reducing its total duration and by introducing gene expression as biomarker of differentiation, which might be very interesting for in vitro risk assessment embryotoxicity.
\end{abstract}

\section{Introduction}

Toxicity to reproduction has to be mandatorily assessed in developed countries for the registration and authorization of all chemicals with medium and high production volumes. Toxicity to reproduction includes adverse effects of chemicals on fertility, embryotoxicity, teratogenicity, and development. OECD has its own in vivo guidelines for testing either teratogenicity (OECD 414) or toxicity to reproduction (testing simultaneously all the above-stated adverse effects) by performing two generation toxicity assays (OECD 416) [1]. It seems remarkable that there are no in vivo guidelines for testing embryotoxicity, which has to be assayed in OECD guideline 416 [2]. Assays according to OECD-416 guideline are time consuming and expensive as they involve lots of animals. It is estimated that one assay of this kind to test a single chemical requires 3200 animals [3] with an estimated cost of more than $€ 300000$ [4]. Thus, it is obvious that a fast, safe, and reliable in vitro alternative method for performing embryotoxicity risk assessment would be welcomed by industry. Furthermore, it would help to save lots of resources devoted to test other toxicity to reproduction effects accounting after embryonic development, which is especially relevant for the massive screenings performed during the early development stages of chemicals for lots of purposes (i.e., pharmaceuticals, cosmetics, biocides, food additives, etc.).

The only validated methods available for testing embryotoxicity in vitro are the embryonic stem cell test (EST) (see abbreviations), the mouse whole embryo culture, and the micromass method. Of these, EST is the only "pure" in vitro method because it totally suppresses the use of animals [2]. EST uses two mouse cell lines, D3 embryonic stem cells for testing embryotoxicity by monitoring general cytotoxicity and disturbances in their differentiation, and $3 \mathrm{~T} 3$ fibroblasts embryonic cells for testing general cytotoxicity in a nondifferentiating system. EST uses three different end-points, $\mathrm{IC}_{50} \mathrm{D} 3$ and $\mathrm{IC}_{50} 3 \mathrm{~T} 3$, which are defined as the concentration 
of the tested chemical that causes $50 \%$ reduction in the viability of D3 and 3T3 cells, respectively, and ID $_{50}$, defined as the concentration of the tested chemical that causes inhibition of D3 cells differentiation by 50\% [5]. These three endpoints are further integrated into three linear discriminant functions which discriminate the embryotoxic potential of chemicals into three categories: non, weak, and strong embryotoxicity [6].

EST is relatively lengthy because it requires the exposure of cells to tested chemicals for 10 days. Its technical complexity is also relatively high because it includes cell cultures in monolayers to obtain $\mathrm{IC}_{50} \mathrm{D} 3$ and $\mathrm{IC}_{50} 3 \mathrm{~T} 3$ through cytotoxicity assays, as well as the culture of "hanging drop" embryoid bodies (EBs) for testing alterations in the differentiation of D3 cells. EST is also laborious because it entails two changes of culture medium (of three different cultures containing the two different cell lines), which are specifically prepared with all 6-8 different concentrations of the tested chemical. Besides, more than 300 EBs per single test have to be individually seeded and further optically analyzed. Additionally, a main weakness of EST is the need to monitor changes in the D3 EBs differentiation caused by exposure to the assessed chemical. Indeed, it is performed by an individual microscopic inspection of the 10-day differentiated EBs to determine if they are contractile, or not, without considering other relevant circumstances such as the total beating area.

Despite the above-stated drawbacks, EST has overcome a blind interlaboratory validation study sponsored by the European Centre for Validation of Alternative Methods (ECVAM) that considers EST ready for the in vitro screening embryotoxicity of chemicals [7]. However, ECVAM also considers that EST is still not ready for regulatory purposes and that its performance has to be improved by adopting several approaches. In this way, some of ECVAM's suggestions to be implemented in the EST protocol [8] are to introduce molecular end-points (for a better quantification of D3 cells differentiation) and to introduce end-points for monitoring the differentiation to the three main embryonic lineages (and not only mesoderm-derived cardiomyocytes).

In this work, we followed ECVAM's suggestions by using the expression of several genes deriving from mesoderm, endoderm, and ectoderm as biomarkers of differentiation. We used these biomarkers to estimate ID $_{50}$ based on molecular approaches. We found that the linear discriminating functions originating from the EST protocol were able to correctly predict the embryotoxicity of the strong embryotoxic chemical 5-fluorouracil (5-FU), the weak embryotoxic chemical 5,5-diphenylhydantoin (DPH), and the nonembryotoxic chemical saccharin. We also proposed other improvements to the EST protocol by employing monolayer cultures instead of hanging drops EBs and by cutting the exposure time from 10 days to 5 days.

\section{Materials and Methods}

2.1. Cell Cultures. D3 cells were grown on monolayers in undifferentiated state on 75-mm plates in Dulbecco's modified eagle medium (DMEM), medium supplemented with $15 \%$ heat-inactivated fetal bovine serum, $1 \%$ nonessential amino acids, 50 units of penicillin $/ \mathrm{mL}, 100 \mu \mathrm{g}$ streptomycin $/ \mathrm{mL}$, $0.1 \mathrm{mM} \beta$-mercaptoethanol, and 1000 units of leukemia inhibition factor (LIF) $/ \mathrm{mL}$. Undifferentiated cells were incubated at $37^{\circ} \mathrm{C}$ in an atmosphere with $1.5 \% \mathrm{CO}_{2}$ and $95 \%$ humidity. For culturing D3 cells under spontaneous differentiation, LIF was removed from the medium culture, and the $\mathrm{CO}_{2}$ concentration was increased to $5 \%$.

3T3 cells were grown on monolayers on $75 \mathrm{~mm}$ plates in DMEM medium supplemented with $10 \%$ calf serum, 50 units of penicillin $/ \mathrm{mL}$, and $100 \mu \mathrm{g}$ streptomycin $/ \mathrm{mL}$. Cells were incubated at $37^{\circ} \mathrm{C}$ in an atmosphere with $5 \% \mathrm{CO}_{2}$ and $95 \%$ humidity.

2.2. Cellular Exposures to Chemicals. Fresh 5-FU, DPH, or saccharin were added to the medium cultures at the appropriate concentrations just before starting exposures. D3 cells under spontaneous differentiation were cultured for 5 days on monolayers in P100 Petri dishes (for gene expression monitoring) or in 96-well plates (for cytotoxicity assays) as stated above. 3T3 cells were cultured in 96-well plates as described above and were also exposed to 5-FU, DPH, or saccharin for 5 days. In all cases, the culture medium was changed on day 3 of exposure.

2.3. Cytotoxicity Assays. The cytotoxicity caused by exposure to 5-FU, DPH, and saccharin was assayed with the 3-(4,5-dimethylthiazol-2-yl)-2,5-diphenyltetrazoliumbromide (MTT) assay, which is the cytotoxicity assay used in the EST protocol [6]. This test is based on the ability of mitochondrial dehydrogenases to convert the yellow substrate MTT into a dark blue formazan product.

D3 and 3T3 cells were seeded at 20000 cells/well and incubated as described above in the presence of different 5-FU, DPH, or saccharin concentrations. On day 5 of exposure, chemicals were removed, and cells were incubated with $1 \mathrm{mg}$ MTT/mL for 3 hours. At the end of this period, MTT was removed, and cells were washed with phosphate buffer saline. Finally, $100 \mu \mathrm{L}$ of dimethyl sulfoxide/well were added to lysate cells, and the generated formazan was monitored recording absorbance at $570 \mathrm{~nm}$. It was assumed that control cultures (not exposed to 5-FU, DPH, or saccharin) presented maximum viability, and the results were expressed as a percentage as regards these controls. Each condition was assayed in 12 independent wells.

2.4. Quantification of the Gene Expression. The expression of the genes proposed as biomarkers of differentiation was recorded by quantitative RT-PCR with three independent plates per assayed condition.

Cell cultures were trypsinized after exposure to 5-FU, DPH, or saccharin, and total RNA was extracted with Tripure according to Chomczynski and Sacchi [9]. RNA was quantified and purity determined according to the $260 / 280 \mathrm{~nm}$ optical density ratio. One $\mu \mathrm{g}$ of RNA was reverse transcribed using Expand Reverse Transcriptase and oligo-dT primers (Roche) according to the manufacturer's recommendations.

All the genes (except Pnpla6) were assayed using the Light Cycler Fast Start DNA Master PLUS SYBR Green I 
TABLE 1: Primer sequences and annealing temperatures used in the quantitative RT-PCR experiments.

\begin{tabular}{lccc}
\hline Gene & \multicolumn{1}{c}{$5^{\prime}-3^{\prime}$ oligo } & $3^{\prime}-5^{\prime}$ oligo & $\mathrm{T}\left({ }^{\circ} \mathrm{C}\right)$ \\
\hline Actin & CCCTAGGCACCAGGGTGTGA & TCCCAGTTGGTAACAATGCCA & 62 \\
Afp & GCTGCAAAGCTGACAACAAG & GGTTGTTGCCTGGAGGTTTC & 63 \\
vegfa & CGTTCACTGTGAGCCTTGTTCAG & GCCTTGCAACGCGAGTCTGT & 60 \\
Hdac7 & CCATGTTTCTGCCAAATGTTTTGG & GCCGTGAGGTCATGTCCACC & 63 \\
Flk & CAGCCAGACAGACAGTGGGATGGTC & CCGAGGCCACAGACTCCCTGCTT & 61 \\
Nes & GCTTTCCTGACCCCAAGCTG & GGCAAGGGGGAAGAGAAGGA & 61 \\
\hline
\end{tabular}

TABle 2: The linear discriminant functions and classification criteria considered in EST for assessing the embryotoxicity potential of chemicals. Data taken from [11]. $\mathrm{IC}_{50} \mathrm{D} 3$ was defined as the concentration that reduces the viability of D3 cells by $50 \%$ after 10 days of exposure. $\mathrm{IC}_{50} 3 \mathrm{~T} 3$ was defined as the concentration that reduces the viability of $3 \mathrm{~T} 3$ cells by $50 \%$ after 10 days of exposure. ID $\mathrm{I}_{50}$ was defined as the concentration that inhibits the spontaneous differentiation of $\mathrm{D} 3$ embryoid bodies to contractile cardiomyocytes by $50 \%$. $\mathrm{IC}_{50} \mathrm{D} 3$, $\mathrm{IC}_{50} 3 \mathrm{~T} 3$, and $\mathrm{ID}_{50}$ must necessarily be expressed in $\mu \mathrm{g} / \mathrm{mL}$.

\begin{tabular}{lcc}
\hline & $\mathrm{I}=5.916 \log \left(\mathrm{IC}_{50} 3 \mathrm{~T} 3\right)+3.500 \log \left(\mathrm{IC}_{50} \mathrm{D} 3\right)-5.307\left[\left(\mathrm{IC}_{50} 3 \mathrm{~T} 3-\mathrm{ID}_{50}\right) / \mathrm{IC}_{50} 3 \mathrm{~T} 3\right]-15.27$ \\
& $\mathrm{II}=3.651 \log \left(\mathrm{IC}_{50} 3 \mathrm{~T} 3\right)+2.394 \log \left(\mathrm{IC}_{50} \mathrm{D} 3\right)-2.033\left[\left(\mathrm{IC}_{50} 3 \mathrm{~T} 3-\mathrm{ID}_{50}\right) / \mathrm{IC}_{50} 3 \mathrm{~T} 3\right]-6.85$ \\
& $\mathrm{III}=-0.125 \log \left(\mathrm{IC}_{50} 3 \mathrm{~T} 3\right)-1.917 \log \left(\mathrm{IC}_{50} \mathrm{D} 3\right)+1.500\left[\left(\mathrm{IC}_{50} 3 \mathrm{~T} 3-\mathrm{ID}_{50}\right) / \mathrm{IC}_{50} 3 \mathrm{~T} 3\right]-2.67$ \\
\hline Strong embryotoxic if & Weak embryotoxic if & Non embryotoxic if \\
$\mathrm{III}>$ I and III $>$ II & II $>$ I and II $>$ III & I $>$ II and I $>$ III \\
\hline
\end{tabular}

kit (Roche). The PCR program consisted in an initial step at $95^{\circ} \mathrm{C}$ for 10 minutes followed by 40 cycles of 10 seconds denaturing at $95^{\circ} \mathrm{C}, 7$ seconds at the respective annealing temperature, and 12 seconds at $72^{\circ} \mathrm{C}$, plus a final melting curve step. Table 1 indicates the primer sequences and the annealing temperatures employed for each gene. The Pnpla6 expression was monitored in the samples analyzed with the specific Taqman kit supplied by Applied Biosystems.

Quantification was performed by considering $2^{(-\Delta \Delta \mathrm{Ct})}$ calculations [10] with the Step-One software, v2.0.1 (Applied Biosystem). $\beta$-Actin was used as an invariant internal control for each sample.

2.5. Results Validation. The performance of the proposed end-points was validated by applying the same linear discriminant functions and by following the classification criteria used in the EST protocol. These functions and criteria are summarized in Table 2.

2.6. Statistical Significance. Differences between the gene expression of the control and chemical-exposed cultures were statistically analyzed with Student's $t$-tests performed with Graph-Pad Instat (v 3.06). The level of significance $(P)$ is indicated in each case.

\section{Results}

3.1. Cytotoxicity of 5-FU, DPH, and Saccharin. The cytotoxicity caused by $5-\mathrm{FU}, \mathrm{DPH}$, and saccharin after 5 days of exposure to D3 and 3T3 cells was assayed with the MTT test since these end-points are required to assay embryotoxicity according to EST. 5-FU was more toxic for D3 cells than for $3 \mathrm{~T} 3$ cells (Figure $1(\mathrm{a})$ ). $\mathrm{IC}_{50} \mathrm{D} 3$ was $0.17 \mu \mathrm{g} / \mathrm{mL}$, while $\mathrm{IC}_{50}$ for $3 \mathrm{~T} 3$ cells was recorded to be 2.6 times higher (Table 3 ). We chose the $50 \mathrm{ng} / \mathrm{mL}$ concentration to test the effect of $5-\mathrm{FU}$ on several biomarkers of differentiation which, according to Figure 1(a), would cause a reduction of the viability for D3 and $3 \mathrm{~T} 3$ cells by $15 \%$ and $6 \%$, respectively.

On the opposite to 5-FU, the cytotoxicity of DPH was higher (1.4 times) for 3T3 than for D3 cells (Figure 1(b), Table 3). We studied gene expression on D3 cells exposed for 5 days to $75 \mu \mathrm{g} \mathrm{DPH} / \mathrm{mL}$, which according to Figure 1(b) would cause loss of viability of $28 \%$. The estimated reduction of $3 \mathrm{~T} 3$ cell viability caused by this exposure was $38 \%$.

The $\mathrm{IC}_{50}$ for D3 and 3T3 cells of saccharin were both higher than $1000 \mu \mathrm{g} / \mathrm{mL}$ (Figure 1(c), Table 3). This concentration $(1000 \mu \mathrm{g} / \mathrm{mL})$ was used for testing negative controls in the standard EST tests and was selected for testing its effects on gene expression of D3 cells under spontaneous differentiation.

3.2. Expression of Gene Markers of Differentiation on D3 Cells Exposed to 5-FU, DPH, and Saccharin. We assayed the expression of several genes considered useful as biomarkers of differentiation to propose molecular end-points for monitoring the changes taking place in the process as a result of exposure to embryotoxic chemicals, which would potentially improve the microscopic observation of beating EBs. We found (Figure 2(a)) that the exposure of D3 cells under spontaneous differentiation to $50 \mathrm{ng} 5-\mathrm{FU} / \mathrm{mL}$ for 5 days inhibited the expression of patatin-like phospholipase domain containing 6 (Pnpla6), $\alpha$-fetoprotein (Afp), histone deacetylase 7 (Hdac7), vascular endothelial growth factor A (Vegfa), and nestin (Nes) by $20,74,50,54$, and $46 \%$, respectively. It is also remarkable to note that the expression of fetal liver kinase 1 (Flk1) was also altered but, in this case, we detected an increase in the expression of 2.2 times (Figure 2(a)) instead of inhibition. In all cases, the changes in the expression were statistically significant (Figure 2(a)). Thus, we can estimate that the 5-FU concentrations causing a 50\% reduction in 


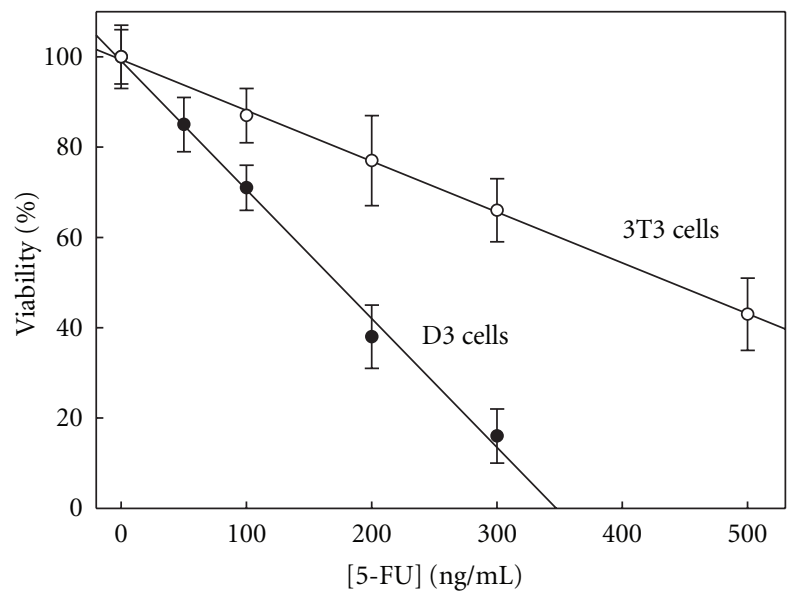

(a)

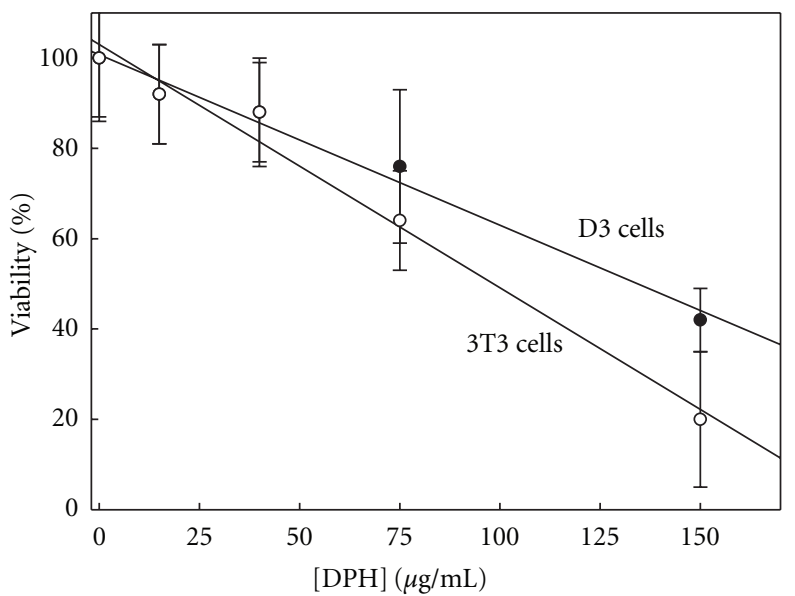

(b)

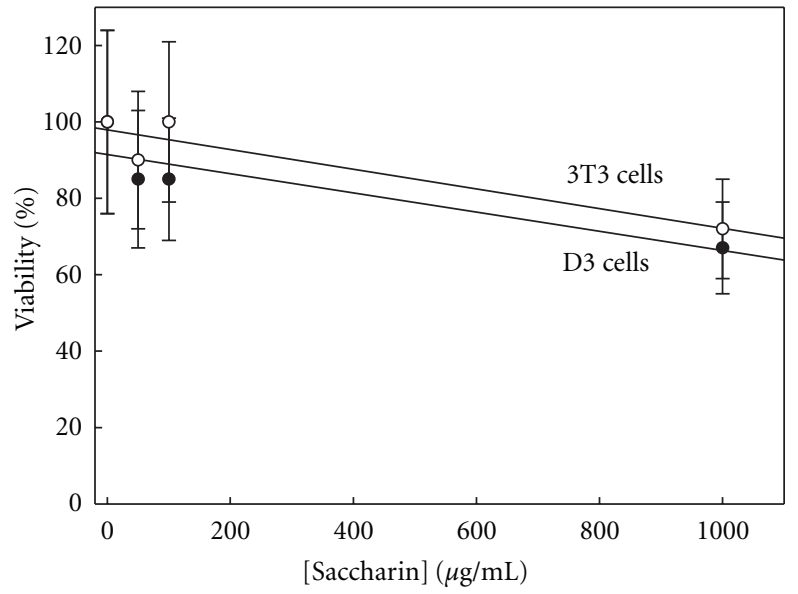

(c)

Figure 1: Effect of 5-FU, DPH, and saccharin on cell viability. D3 and 3T3 cells were cultured on monolayers exposed to 5-FU (a), DPH (b), or saccharin (c) for 5 days. Then the MTT test was performed as described in Section 2. D3 cells were cultured under spontaneous differentiation (in the absence of LIF). The results are expressed as a percentage of absorbance at $570 \mathrm{~nm}$ with regards to the control cultures, which were not exposed to 5-FU, DPH, or saccharin. Each condition was assayed with twelve independent wells.

the expression of the assayed biomarkers (which could be considered the equivalent to the $\mathrm{ID}_{50}$ end-point in EST) would be around $50 \mathrm{ng} / \mathrm{mL}$ for Hdac7, Vegfa, and Nes, higher (but in the same order of magnitude) than $50 \mathrm{ng} / \mathrm{mL}$ for Pnpla6 and lower than $50 \mathrm{ng} / \mathrm{mL}$ for Afp (Figure 2, Table 3).

The exposure ( 5 days to $75 \mu \mathrm{g} / \mathrm{mL}$ ) to DPH of D3 differentiating cells reduced the expression of Pnpla6, Afp, Hdac 7, Vegfa, and Nes to $89,48,74,56$, and $48 \%$, respectively, of nonexposed differentiating cells (Figure 2(b)). DPH also increased expression of Flk 1 in a similar extension (2.1 times) as 5-FU did (Figure 2(b)). These changes in the gene expression were all statistically significant except for Pnpla6 and Hdac7. These records allow estimating that concentrations of DPH causing reduction of $50 \%$ in the expression of Afp, Nes, and Vegfa would be around $75 \mu \mathrm{g} / \mathrm{mL}$, and slightly higher for Pnpla6 and Hdac7.

The exposure of D3 cells to $1000 \mu \mathrm{g}$ saccharin/mL during 5 days causes no significant alterations in the expression of Pnpla6, Vegfa, and Flk1, reductions in the expression of Hdac7 (26\%) and Nes (49\%), and a strong increase (4.4 times) in the expression of Afp (Figure 2(c)).
3.3. Tested Biomarkers Ability to Assign Embryotoxic Potential. We validated the expression of our biomarker genes as regards their ability to detect and classify embryotoxic chemicals using the same linear discriminant functions employed in EST with $\mathrm{ID}_{50}$ as the 5-FU, DPH, and saccharin concentrations which inhibit the expression of the gene by $50 \%$ (Table 3). We found that Pnpla6, Afp, Vegfa, Hdac7, and Nes were able to assign the label of strong embryotoxicant to 5FU and weak embryotoxicant to DPH, in accordance with its in vivo toxicity, and also as was previously reported with standard EST [5]. Pnpla6, Flk1, Vegfa, Hdac7, and Nes also properly labeled saccharin as nonembryotoxic chemical (Table 3).

\section{Discussion}

We tested the expression of the biomarker genes of early differentiation as possible end-points to improve EST performance. At the same time, we proposed a reduction in the total test duration and a simplification of the process since we used monolayer cultures instead of "hanging drops" 
TABLE 3: Biomarkers validation. The capability of the tested biomarkers to assign an embryotoxic potential to chemicals was validated using the linear discriminate functions and the EST protocol criteria according to what Table 2 displays. $\mathrm{IC}_{50} \mathrm{D}_{3}$ and $\mathrm{ID}_{50} 3 \mathrm{~T} 3$ records were obtained from Figure 1, while $\mathrm{ID}_{50}$ was obtained from Figure 2.

\begin{tabular}{|c|c|c|c|c|c|c|c|c|}
\hline \multirow[b]{2}{*}{ Substance } & \multirow[b]{2}{*}{ Gene } & \multirow{2}{*}{$\begin{array}{l}\mathrm{IC}_{50} \mathrm{D} 3 \\
(\mu \mathrm{g} / \mathrm{mL})\end{array}$} & \multirow{2}{*}{$\begin{array}{l}\mathrm{ID}_{50} 3 \mathrm{~T} 3 \\
(\mu \mathrm{g} / \mathrm{mL})\end{array}$} & \multirow{2}{*}{$\begin{array}{c}\mathrm{ID}_{50} \\
(\mu \mathrm{g} / \mathrm{mL})\end{array}$} & \multicolumn{3}{|c|}{ Linear discriminant functions } & \multirow[b]{2}{*}{ CLA } \\
\hline & & & & & I & II & III & \\
\hline \multicolumn{9}{|l|}{ 5-FU } \\
\hline & Pnpla6 & 0.17 & 0.44 & $>0.05$ & $-25+12 \mathrm{ID}_{50}$ & $-12+4.6 \mathrm{ID}_{50}$ & $0.37-3.4 \mathrm{ID}_{50}$ & $S$ \\
\hline & $A f p$ & 0.17 & 0.44 & $<0.05$ & $-25+12 \mathrm{ID}_{50}$ & $-12+4.6 \mathrm{ID}_{50}$ & $0.37-3.4 \mathrm{ID}_{50}$ & S \\
\hline & Hdac7, Vegfa, Nes & 0.17 & 0.44 & 0.050 & -25 & -12 & 0.18 & S \\
\hline & $F l k 1$ & 0.17 & 0.44 & NA & - & - & - & NA \\
\hline \multicolumn{9}{|l|}{$\mathrm{DPH}$} \\
\hline & Nes, Vegfa, Afp & 130 & 97 & 75 & 2.6 & 5.0 & -6.6 & $\mathrm{~W}$ \\
\hline & Pnpla6, Hdac7 & 130 & 97 & $>75$ & $-1.4+0.05 \mathrm{ID}_{50}$ & $3.5+0.02 \mathrm{ID}_{50}$ & $-5.5-0.02 \mathrm{ID}_{50}$ & $\mathrm{~W}$ \\
\hline & $F l k 1$ & 130 & 97 & NA & - & - & - & NA \\
\hline \multicolumn{9}{|l|}{ Saccharin } \\
\hline & Nes & 1850 & 1640 & 1000 & 13 & 12 & -8 & $\mathrm{NON}$ \\
\hline & $\begin{array}{l}\text { Pnpla6, Hdac7, } \\
\text { Vegfa, Flk1, Nes }\end{array}$ & 1850 & 1640 & $>1000$ & $10+0.003 \mathrm{ID}_{50}$ & $11+0.001 \mathrm{ID}_{50}$ & $\begin{array}{c}-7.8- \\
0.0008 \mathrm{ID}_{50}\end{array}$ & $\mathrm{NON}$ \\
\hline & $A f p$ & 1850 & 1640 & NA & - & - & - & NA \\
\hline
\end{tabular}

CLA: classification of embryotoxicity; S: strong embryotoxicant; W: weak embryotoxicant; NON: nonembryotoxicant; NA: not applicable.

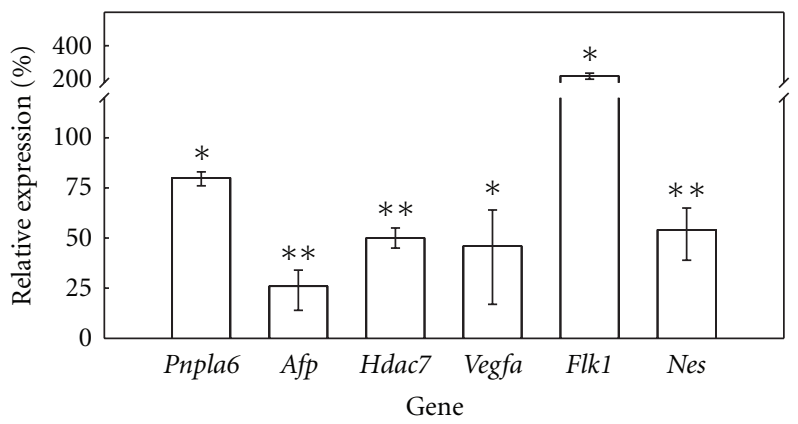

(a)

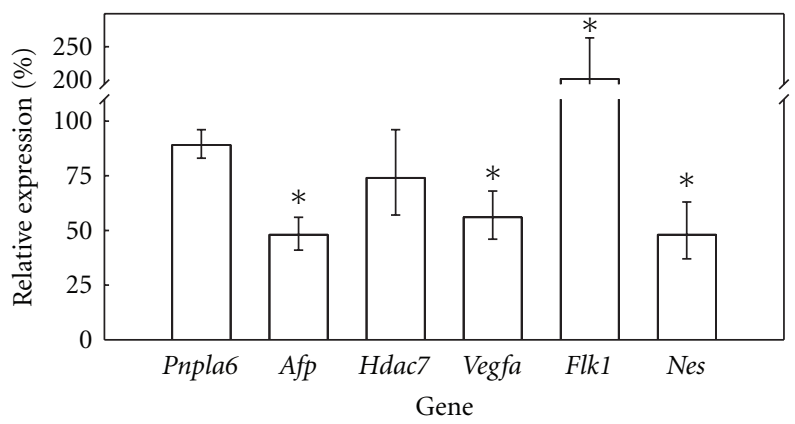

(b)

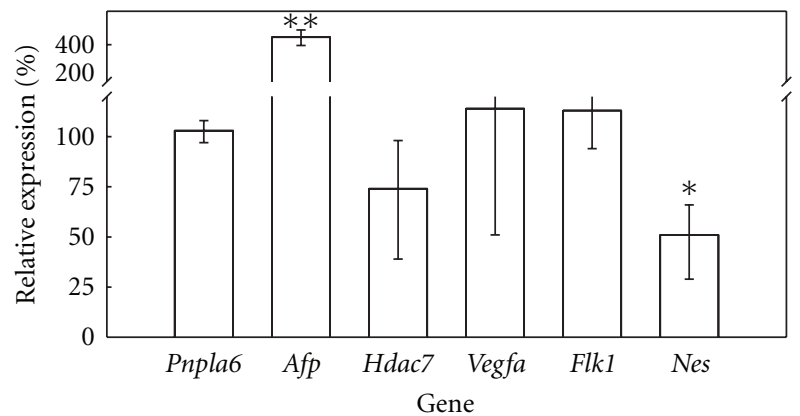

(c)

FIGURE 2: Effect of 5-FU, DPH, and saccharin on D3 differentiation. Monolayer cultures of D3 cells under spontaneous differentiation (in the absence of LIF) were exposed to either $50 \mathrm{ng} 5-\mathrm{FU} / \mathrm{mL}$ (a), or $75 \mu \mathrm{g} \mathrm{DPH} / \mathrm{mL}$ (b), or $1000 \mu \mathrm{g}$ saccharin/mL (c) over 5 days. When exposure ended, RNA was extracted, and the gene expression of the biomarkers of differentiation was assayed by quantitative RT-PCR according to the procedure described in Section 2. The gene expression was expressed as a percentage as regards the control cultures (not exposed to chemicals). Each condition (control and exposed cultures) was assayed in three independent plates. ( $*$ : statistically different from controls for $P<0.05 ; * *$ : statistically different from controls for $P<0.01$ ). 
EBs. The implementation of changes to EST would refine its predictability and allow its future use for regulatory purposes, which would prove useful for the risk assessment of embryotoxicity, and subsequently for toxicity to reproduction.

4.1. Cytotoxicity. We found that 5-FU was 2.6 times more toxic to D3 cells than to $3 \mathrm{~T} 3$ cells (Table 3 ), which was expected since 5-FU was classified as a strong embryotoxicant. These results are comparable to those found in the EST validation study sponsored by ECVAM, where 5-FU was found to be 3.3 times more toxic for D3 cells than for 3T3 cells [6]. This slight difference can be justified on the basis of differences in the exposure (10 days in the case of the EST validation study and 5 days in our work). This difference also justifies that our recorded $\mathrm{IC}_{50}$ was 1.8 and 1.5 times higher for D3 and 3T3, respectively, than the values recorded with the standard EST protocol [6]. The $\mathrm{IC}_{50}$ found in this study for $3 \mathrm{~T} 3$ cells exposed to DPH was 1.7 times higher than the record obtained in the ECVAM's EST validation study [6], which is in concordance with differences found in the case of 5-FU. The cytotoxicity records found for D3 and 3T3 cells exposed to saccharin were also consistent with published results because we also found figures higher than $1000 \mu \mathrm{g} / \mathrm{mL}$ [6].

4.2. Expression of Biomarkers of Differentiation. Pnpla6 is the gene that codifies for a protein called neuropathy target esterase (NTE). NTE is a target of a neurodegenerative syndrome caused by certain organophosphorus pesticides. Additionally, homozygous $\mathrm{NTE}^{-/-}$mice embryos were not viable due to failures in vasculogenesis [12], and although heterozygous $\mathrm{NTE}^{+/-}$mice embryos were viable, the resulting animals displayed alterations in the nervous system [13]. We previously reported that Pnpla6 is expressed constitutively in D3 cells although a peak in expression is reached in initial differentiation stages [14]. All these data indicate that Pnpla6 may play critical roles in normal nervous system development (ectoderm-derived tissue) and blood vessels (endoderm-derived tissues), suggesting that this gene is a good candidate to be used as a biomarker of early differentiation. We found that 5-FU and DPH caused reductions (statistically significant in the case of 5-FU) in the expression of Pnpla6 under our assay conditions (Figures 2(a) and 2(b)), indicating that Pnpla6 might be used for detecting exposure to embryotoxic chemicals by monitoring changes in differentiation.

Afp is typically considered a biomarker of the visceral endoderm [15]. Exposure of D3 cells under differentiation to $50 \mathrm{ng} 5-\mathrm{FU} / \mathrm{mL}$ and to $75 \mu \mathrm{g} \mathrm{DPH} / \mathrm{mL}$ inhibited the $A f p$ expression by $74 \%$ (Figure $2(\mathrm{a})$ ) and 52\% (Figure 2(b)), respectively, which suggests that $A f p$ is a very sensitive biomarker of exposure to embryotoxicants. These results are supported by other previous reports which found that the expression of this gene was inhibited in 20-day-old EBs exposed to 5-FU concentrations several orders of magnitude lower than $\mathrm{IC}_{50}$ [16]. In our case, we have demonstrated that Afp's sensitivity as a biomarker is maintained, even only after 5 days of differentiation.
Vegfa and Hdac7 are considered endoderm biomarkers since the former is involved in the vasculogenesis of yolk sac and hematopoiesis [17], while the latter is implicated in vasculogenesis, endothelial cells migration, and vascular integrity maintenance [18]. The expression of both genes was inhibited by around $50 \%$ after 5 days of exposure to 5 -FU or DPH (Figures 2(a) and 2(b)), suggesting that both genes can be used for our purposes. The expression of Vegfa has also been previously proposed as a molecular end-point for EST [19], although in our case, we cut the exposure time by half to demonstrate that the gene maintains its good performance as a biomarker of differentiation. To our knowledge, this is the first proposal of $\mathrm{Hdac7}$ as a biomarker of differentiation to be used in EST.

Nes codifies for neurofilament proteins and, therefore, plays a critical role in maintaining cellular integrity [20]. We found a statistically significant reduction in the expression of $\mathrm{Nes}$ as a result of cell exposure to 5-FU, DPH, and saccharin (Figure 2), which indicates that Nes might be a good biomarker of exposure to embryotoxicants, at least in D3 cells, as they displayed good compromise in differentiation toward the neuroectoderm when cultured in monolayers [21].

Flk1 is an early mesodermal biomarker [22], which is also altered by 5 -FU exposure (Figure 2). However, unlike other assayed biomarkers, 5-FU and DPH led to increases of expression instead of inhibitions (Figures 2(a) and 2(b)), which means that Flk1 is unsuitable for use in accordance with the EST approach since its mathematical discriminant function was developed considering end-points which were underexpressed as regards the control and not overexpressed as in Flk1 in our study. Nevertheless, changes in the expression of Flk1 were statistically significant, and this information can be valuable as it complements the information obtained for other biomarkers.

\subsection{Performance of Biomarkers for Discrimination of Embry-} otoxicant Potency. 5-FU is a well-known in vivo embryotoxic agent that has been labeled by EST as a strong embryotoxicant (it is included as a positive control in the standard EST protocol). We applied the mathematical functions of EST to our results by considering $\mathrm{ID}_{50}$ as the value of the 5-FU concentration that inhibited the expression of each biomarker by $50 \%$ to determine if our proposed approach yields the same results as the standard protocol. We found that Vegfa, Hdac7, and Nes predicted that 5-FU was a strong embryotoxicant (function III > function I and function III > function II) (Table 3). We could not estimate ID $_{50}$ for Pnpla6 but, according to Figure 2(a), we can establish that it is higher than $50 \mathrm{ng} / \mathrm{mL}$. The analysis done of the discriminant functions with the available data demonstrated that the conditions to be labeled as strong embryotoxic (function III $>$ function I and function III > function II) were lost only for an $\mathrm{ID}_{50}$ higher than $1.5 \mu \mathrm{g} / \mathrm{mL}$. Figure 1(a) illustrates that this exposure would cause total loss of the viability of both the D3 and 3T3 cells, therefore suggesting that if $\mathrm{ID}_{50}$ for Pnpla6 was determined, then 5-FU would also be labeled as a strong embryotoxicant. The $\mathrm{ID}_{50}$ for $A f p$ could not be determined with the available data, but it is concluded that it must be lower than $50 \mathrm{ng} / \mathrm{mL}$ (Figure 2(a)). However, with 
the available information, the analysis of the discriminant functions once again demonstrated that if $\mathrm{ID}_{50}<50 \mathrm{ng} / \mathrm{mL}$, then necessarily III > II and III > I; therefore, 5-FU was correctly classified as a strong embryotoxicant when using Afp as a biomarker of differentiation.

DPH is a well-known in vivo embryotoxic agent that has been labeled by EST as a weak embryotoxicant. When we applied the above-explained approach, we found that in the case of Nes, Vegfa, and Afp, function II was always higher than functions I and II (Table 3), which led to necessarily classify DPH as weak embryotoxicant as EST does. The DPH concentrations with capability to inhibit $50 \%$ of the expression of Pnpla6 and Hdac7 could not be exactly estimated but according to Figure 2(b) should be in the same order of magnitude as $75 \mu \mathrm{g} / \mathrm{mL}$, which according to $\mathrm{IC}_{50}$ records yields the functions I, II, and III as was stated in Table 3. In this situation and taking into consideration that $\mathrm{ID}_{50}$ should necessarily be positive, II always will be higher than III, and II will be higher than I (the needed condition to label DPH as weak embryotoxicant) for $\mathrm{ID}_{50}<143 \mu \mathrm{g} / \mathrm{mL}$, which is compatible with data displayed in Figure 2(b) where we demonstrated that $75 \mu \mathrm{g} D P H / m L$ was able to inhibit 11 and $26 \%$ of Pnpla6 and Hdac7 expression, respectively.

The expression of Nes was inhibited by $50 \%$ by the exposure to $1000 \mu \mathrm{g}$ saccharin $/ \mathrm{mL}$ (Figure 2(c)). Considering the records for $\mathrm{IC}_{50}$, we found that saccharin must be classified as nonembryotoxicant, since I > II and I > III (Table 3). We also found that $\mathrm{ID}_{50}$ for Pnpla6, Hdac7, Vegfa, Flk1, and Nes was always higher than $1000 \mu \mathrm{g}$ saccharin/mL, which becomes EST discriminant functions in equations showed in Table 3. Considering that $\mathrm{ID}_{50}$ must be necessarily positive, it supposes that I will be always higher than III and higher than II for $\mathrm{ID}_{50}$ higher than $420 \mu \mathrm{g} / \mathrm{mL}$, which is consistent to results shown in Figure 2(c) and led to necessarily classify saccharin as nonembryotoxicant, as was established by the EST method.

\section{Conclusions}

We propose implementing the expression of 6 different biomarkers of differentiation to EST end-points, which would improve the performance of this method for risk assessment (specifically in the step of hazard identification). These biomarkers have successfully predicted the embryotoxicity of 5-FU, DPH, and saccharin, but an assessment with another embryotoxicant chemicals is pending. In addition, we introduced three other improvements: reducing the total test time by half, employing monolayer cultures instead of more technically complex techniques to manage EBs, and the possibility to assess several end-points (the expression of several genes) for the same exposed cells.

\section{Abbreviations}

5-FU: 5-fluorouracil

Afp: $\quad \alpha$-fetoprotein

DMEM: Dulbecco's modified eagle medium

DPH: 5,5-diphenylhydantoin

EBs: Embryoid bodies
ECVAM: European Centre for Validation of Alternative Methods

EST: Embryonic stem cell test

Flk1: $\quad$ Fetal liver kinase 1

Hdac7: Histone deacetylase 7

LIF: Leukemia inhibition factor

MTT: $\quad 3$-(4,5-dimethylthiazol-2-yl)-2,5diphenyltetrazolium bromide

Nes: Nestin

NTE: Neuropathy target esterase

Pnpla6: Patatin-like phospholipase domain containing 6

Vegfa: Vascular endothelial growth factor A.

\section{Acknowledgment}

The authors thank Professor Vicente Micol from the Institute of Molecular and Cell Biology at the Miguel Hernández University, Elche (Spain) for kindly supplying the 3T3 fibroblast cells.

\section{References}

[1] C. Estevan, D. Pamies, M. A. Sogorb, and E. Vilanova, "OECD guidelines and validated methods for in vivo testing of reproductive toxicity," in Reproductive and Developmental Toxicology, R. C. Gupta, Ed., p. 123, Academic Press, Hopkinsville, Ky, USA, 2011.

[2] D. Pamies, C. Estevan, M. A. Sogorb, and E. Vilanova, "Mechanism-based models in reproductive and developmental toxicology," in Reproductive and Developmental Toxicology, R. C. Gupta, Ed., p. 135, Academic Press, Hopkinsville, Ky, USA, 2011.

[3] T. Höfer, I. Gerner, U. Gundert-Remy et al., "Animal testing and alternative approaches for the human health risk assessment under the proposed new European chemicals regulation," Archives of Toxicology, vol. 78, no. 10, pp. 549-564, 2004.

[4] M. Fleischer, "Testing costs and testing capacity according to the REACH requirements - results of a survey of independent and corporate GLP laboratories in the EU and Switzerland," Journal of Business Chemistry, vol. 4, no. 3, pp. 96-114, 2007.

[5] E. Genschow, H. Spielmann, G. Scholz et al., "The ECVAM international validation study on in vitro embryotoxicity tests: results of the definitive phase and evaluation of prediction models," ATLA Alternatives to Laboratory Animals, vol. 30, no. 2, pp. 151-176, 2002.

[6] E. Genschow, H. Spielmann, G. Scholz et al., "Validation of the embryonic stem cell test in the international ECVAM validation study on three in vitro embryotoxicity tests," ATLA Alternatives to Laboratory Animals, vol. 32, no. 3, pp. 209-244, 2004.

[7] ESAC (European Centre for Validation of Alternative Methods (ECVAM) Scientific Advisory Committee), "The Use of Scientifically-Validated in Vitro Tests for Embryotoxicity," 2002, http://ecvam.jrc.ec.europa.eu/.

[8] H. Spielmann, A. Seiler, S. Bremer et al., "The practical application of three validated in vitro embryotoxicity tests. The report and recommendations of an ECVAM/ZEBET workshop (ECVAM workshop 57)," Alternatives to Laboratory Animals, vol. 34, no. 5, pp. 527-538, 2006. 
[9] P. Chomczynski and N. Sacchi, "Single-step method of RNA isolation by acid guanidinium thiocyanate-phenol-chloroform extraction," Analytical Biochemistry, vol. 162, no. 1, pp. 156-159, 1987.

[10] K. J. Livak and T. D. Schmittgen, "Analysis of relative gene expression data using real-time quantitative PCR and the $2^{-\Delta \Delta C_{\mathrm{T}}}$ method," Methods, vol. 25, no. 4, pp. 402-408, 2001.

[11] E. Genschow, G. Scholz, N. Brown et al., "Development of prediction models for three in vitro embryotoxicity tests in an ECVAM validation study," In Vitro and Molecular Toxicology, vol. 13, no. 1, pp. 51-65, 2000.

[12] M. Moser, Y. Li, K. Vaupel et al., "Placental failure and impaired vasculogenesis result in embryonic lethality for neuropathy target esterase-deficient mice," Molecular and Cellular Biology, vol. 24, no. 4, pp. 1667-1679, 2004.

[13] C. J. Winrow, M. L. Hemming, D. M. Allen, G. B. Quistad, J. E. Casida, and C. Barlow, "Loss of neuropathy target esterase in mice links organophosphate exposure to hyperactivity," Nature Genetics, vol. 33, no. 4, pp. 477-485, 2003.

[14] D. Pamies, J. A. Reig, E. Vilanova, and M. A. Sogorb, "Expression of neuropathy target esterase in mouse embryonic stem cells during differentiation," Archives of Toxicology, vol. 84, no. 6, pp. 481-491, 2010.

[15] L. Jin, L. Long, M. A. Green, and B. T. Spear, "The alphafetoprotein enhancer region activates the albumin and alphafetoprotein promoters during liver development," Developmental Biology, vol. 336, no. 2, pp. 294-300, 2009.

[16] D. Pamies, N. Vicente-Salar, M. A. Sogorb, E. Roche, and J. A. Reig, "Specific effect of 5-fluorouracil on $\alpha$-fetoprotein gene expression during the in vitro mouse embryonic stem cell differentiation," International Journal of Toxicology, vol. 29, no. 3, pp. 297-304, 2010.

[17] A. Damert, L. Miquerol, M. Gertsentein, W. Risau, and A. Nagy, "Insufficient VEGFA activity in yolk sac endoderm compromises haematopoietic and endothelial differentiation," Development, vol. 129, no. 8, pp. 1881-1892, 2002.

[18] S. Chang, B. D. Young, S. Li, X. Qi, J. A. Richardson, and E. N. Olson, "Histone deacetylase 7 maintains vascular integrity by repressing matrix metalloproteinase 10," Cell, vol. 126, no. 2, pp. 321-334, 2006.

[19] M. Festag, B. Viertel, P. Steinberg, and C. Sehner, "An in vitro embryotoxicity assay based on the disturbance of the differentiation of murine embryonic stem cells into endothelial cells. II. Testing of compounds," Toxicology in Vitro, vol. 21, no. 8, pp. 1631-1640, 2007.

[20] T. Sunabori, A. Tokunaga, T. Nagai et al., "Cell-cycle-specific nestin expression coordinates with morphological changes in embryonic cortical neural progenitors," Journal of Cell Science, vol. 121, no. 8, pp. 1204-1212, 2008.

[21] E. Roche, J. A. Reig, A. Campos et al., "Insulin-secreting cells derived from stem cells: clinical perspectives, hypes and hopes," Transplant Immunology, vol. 15, no. 2, pp. 113-129, 2005.

[22] G. Narazaki, H. Uosaki, M. Teranishi et al., "Directed and systematic differentiation of cardiovascular cells from mouse induced pluripotent stem cells," Circulation, vol. 118, no. 5, pp. 498-506, 2008. 

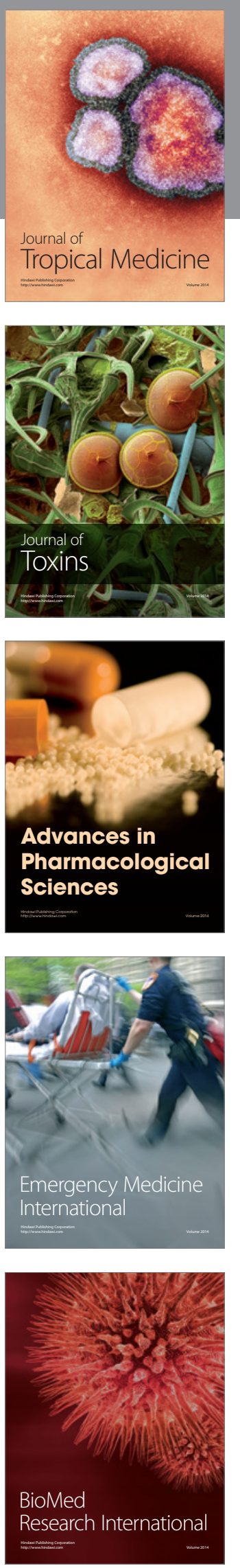
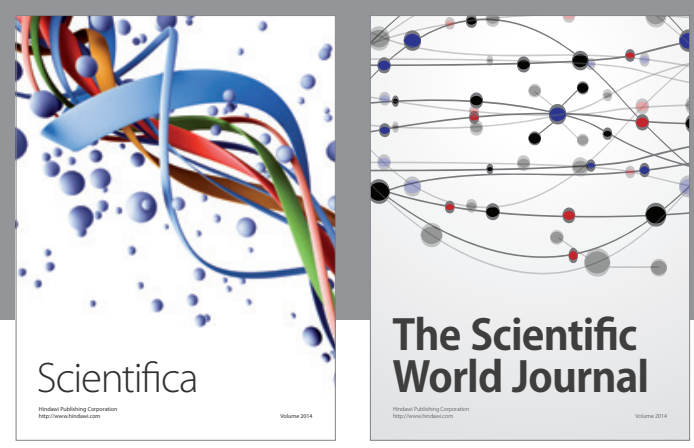

The Scientific World Journal
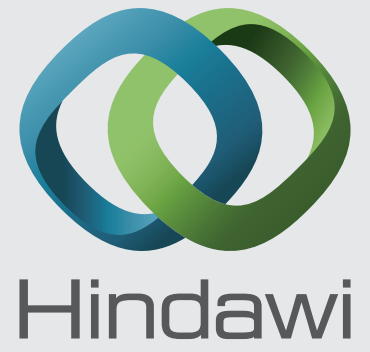

Submit your manuscripts at

http://www.hindawi.com
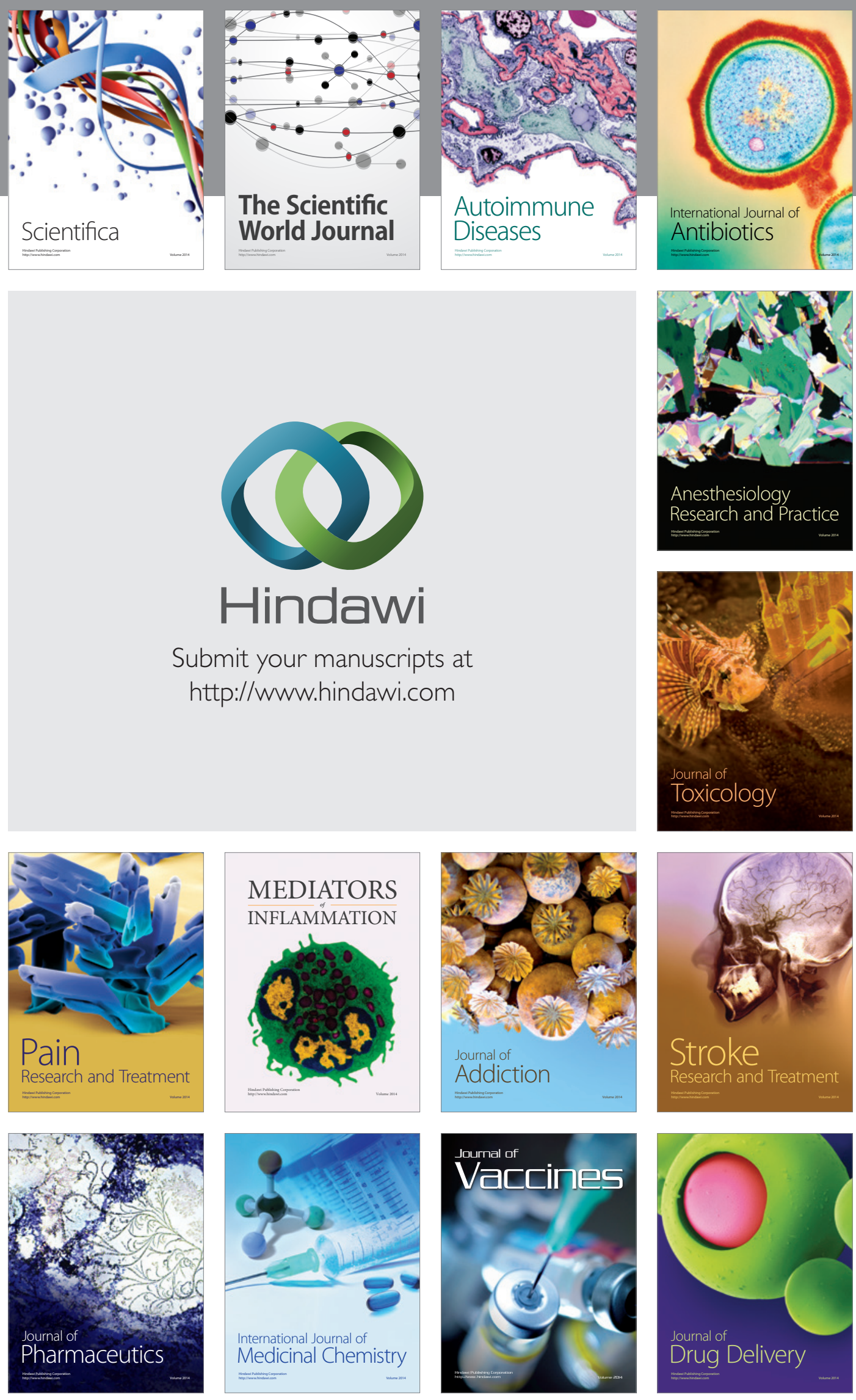